\title{
A Brief Analysis on Management Effectiveness of College Enterprise Education
}

\author{
Jianfeng Luo \\ Jingjiang College, Jiangsu University, Zhenjiang, China \\ Email address: \\ luojianfeng001@126.com
}

\section{To cite this article:}

Jianfeng Luo. A Brief Analysis on Management Effectiveness of College Enterprise Education. Science Journal of Education. Vol. 4, No. 3, 2016, pp. 118-122. doi: 10.11648/j.sjedu.20160403.12

Received: June 22, 2016; Accepted: July 4, 2016; Published: July 18, 2016

\begin{abstract}
Based on the definition and characteristic analysis of management effectiveness, this paper analyzes the reason of the weakness in the management effectiveness of college enterprise education, and explores the following five aspects of improving management effectiveness in college enterprise education, including establishing reasonable enterprise education targets, setting up proper enterprise education curriculum, improving the teachers' professional level, creating the effectiveness evaluation of innovation and enterprise education and feedback mechanism. This paper aims to make maximum use of enterprise education resources, to raise the level and quality of college enterprise education, and to promote college students' entrepreneurship and employment finally.
\end{abstract}

Keywords: College, Enterprise Education, Management Effectiveness

\section{Introduction}

Since the idea of "enterprise education - the third educational passport" was put forward in the international seminar of Education Facing $21^{\text {st }}$ Century in 1989, enterprise education has been actively implemented in various domains including general education, vocational education, cultivating students' entrepreneurship and abilities [1]. Currently, the researches of domestic enterprise education in colleges are mainly focused on experiences from foreign colleges, enterprise education modes, systems, present situation and problems. However, studies on the effectiveness of enterprise education are basically in the blank condition [2]. However, domestic enterprise education starts relatively late, due to inadequate understanding of the key attributives and difficulties in practical application, the effectiveness and profound development of enterprise education are greatly affected. To enhance the research on enterprise education effectiveness is beneficial for colleges to optimize the mechanism and teaching modes, improve the reform and development of enterprise education, and establish a more direct and scientific evaluation system [3]. The problem of how to allocate and utilize enterprise education resources to realize maximal management effectiveness needs more attention and urgent research work.

\section{The Definition and Characteristic of Management Effectiveness in College Enterprise Education}

Management effectiveness is a method to increase useful effectiveness energy by means of improving organizational process, resource allocation and structure. It emphasizes on uniting thoughts by all feasible effectiveness standards to guide operation management activities.

For college enterprise educators, management effectiveness requires colleges to make full use of human, financial and material resources, which will maximize students' development potential by means of various teaching methods. College educators need to strengthen students' consciousness to start an undertaking, impart them knowledge and skills, so that students' viability and competitiveness in entrepreneurial process can be ensured [4].

The management effectiveness of college enterprise education has the following four characteristics: effectiveness, organizational, dynamism and innovativeness.

First of all, the effectiveness of management means that college educators have to integrate human, financial and 
material resources effectively, according to the objective requirement of college enterprise education development. The educators should explore the potential of integrated usable resources to ensure the goal of good performance as well as the sustainable development efficiency in college enterprise education.

Secondly, management effectiveness of college enterprise education has organizational feature. Management effectiveness of college enterprise education, the same as other management methods, is a kind of methods that the specific person, work objects and means are seen as the basis for carrying out work. Therefore, management effectiveness cannot exist independently apart from organization. College enterprise educators should improve the management level of various organizations to raise organizational effectiveness.

Thirdly, the dynamism feature refers to that management effectiveness in college enterprise education is a long-term process from the start to the end, which implies that administrators of college enterprise educators have to explore into the whole process. Educators need to not only make plans of raising management effectiveness, but also take supervision and control over the implementation, adjustment and evaluation of plans, even including the basic operation, work methods and tools of each staff. In this case, measures can be taken in time if things go wrong in some parts.

Fourthly, the innovativeness of management is the demand of developing forward and advancing with times. The backgrounds, policies and methods of establishing a business change with the development of society, so new adaptive management models are required. If the management level of college enterprise education remains stagnant, lacking creative notions and systems, enterprise education work cannot achieve transformation and promotion of dynamic development from old to new qualities.

\section{The Reasons of Weakly Management Effectiveness in Present College Enterprise Education}

\subsection{Enterprise Education Focusing on Formalization}

The enterprise education of our country, a new thing, springs up under the background of higher education popularization. Though specialized enterprise education departments have been set up in many colleges, the misunderstanding of enterprise education exists generally. The knowledge of separating enterprise education from the mainstream education system leads to the problem that colleges usually carry out superficial work, ignoring the essence of enterprise education [5]. Actually, enterprise education, as a significant part in our country's higher education system, is an essential element for measuring the comprehensive strength and competitiveness of a certain college.

Even though some colleges have deep understanding on the significance of enterprise education, due to the restrictions of objective conditions, the teaching models and curriculum setting in colleges are mainly imitated and copied from other countries. So that enterprise education and general teaching are not integrated closely, and the specific enterprise education system has not been established yet. In this case, the degree of students' knowledge and participation is in a bad condition. Moreover, featured enterprise education, suitable for regional and students' characteristics, has not been established. Survey shows that, most of the college student entrepreneurs have not received systematic enterprise education. Meanwhile, the main source of entrepreneurship knowledge obtained by college student entrepreneurs is not the enterprise education in colleges. Survey results are shown in Figure 1 and Figure 2 [6].

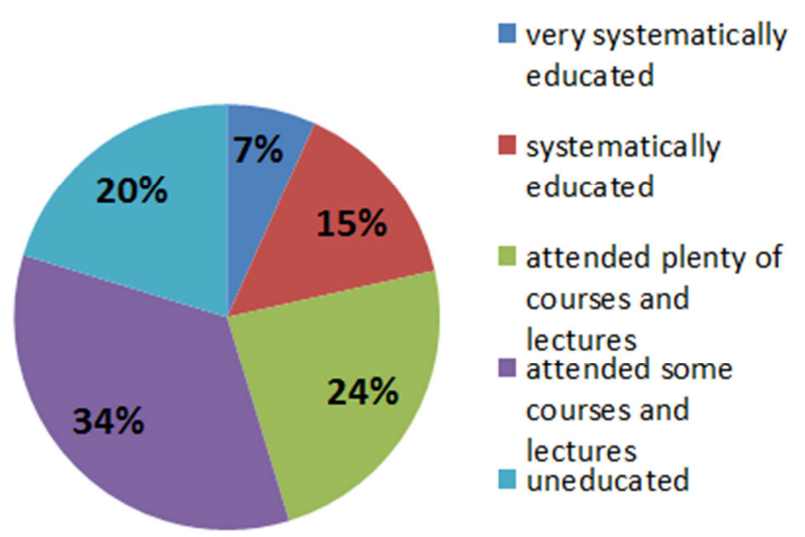

Figure 1. Education Background of College Student Entrepreneurs.

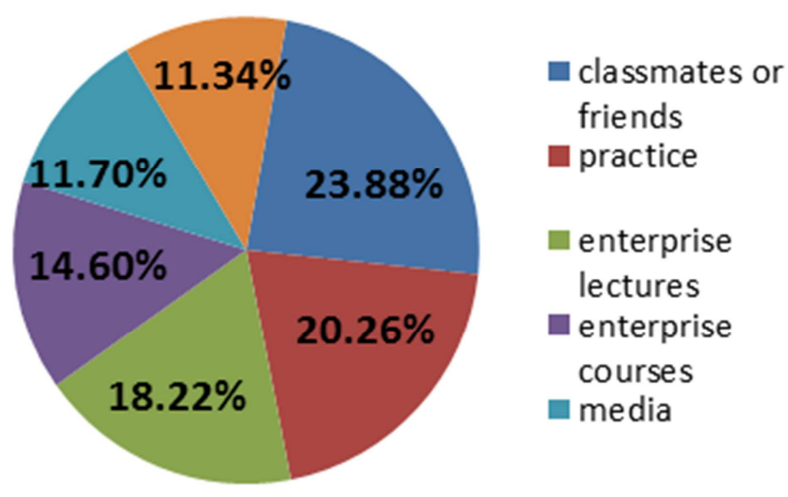

Figure 2. The Sources of Entrepreneurial Knowledge for College Students Entrepreneurs.

\subsection{Enterprise Curriculum Setting Lacking Scientificness and Practicability}

Enterprise education curriculum is the most convenient way to realize entrepreneurship development. However, the development of domestic enterprise education curriculum is inadequate and immethodical [7]. Most of the colleges have weak parts in enterprise education curriculum setting, such as lacking professional enterprise education curriculum and excluding form teaching plans, which causes the inefficiency of enterprise education. Enterprise education curriculum is usually set as a small part of employment instruction course. With the restrictions of curriculum setting and teacher 
resource, there are some problems existing in the present college enterprise education curriculum, covering inflexible and single teaching methods, rigid curriculum styles, students' receptive study, and deficient typical cases.

There are some colleges in which enterprise education enters into a new comprehensive stage. However, there is misunderstanding in teaching methods. The present teaching methods are usually lack of practicability, for example, enterprise knowledge competitions and reports are usually used instead of enterprise education. Enterprise knowledge competitions and reports are beneficial to strengthen students understanding of enterprise policies, develop students' enterprise awareness and passion. However, the knowledge achieved from these competitions and reports are immethodical and partial, on account that these competitions and reports are merely certain kinds of outer manifestation and guidance of enterprise education.

\subsection{Ambiguous Enterprise Education Objectives}

In most colleges, enterprise education is not treated as an independent discipline, but test-oriented education instead [8] Enterprise activities are mainly referred to as creating various program plans and documentation and cultivating so-called "student boss", which causes that college enterprise education is labelled on instrumentalization, utilitarianism and proceduring.

The development report of Chinese college students' employment and entrepreneurship shows that, the entrepreneurship rates of recent years maintain approximately 2.8 percent. Enterprise education targets in some colleges are limited to graduates who have business ideas and needs, while entrepreneurship should be understood in a more generalized way. Enterprise education is a kind of quality-oriented education, which aims to teach students the process of starting business, the operation and management modes of companies, the relative law, regulations and policies. Moreover, it's more important to cultivate students' innovation spirits, teamwork awareness, comprehensive judgment and analysis ability through these enterprise education activities.

\subsection{Unprofessional Teaching Staff of Enterprise Education}

The content of college enterprise education covers different disciplines and various abilities, involving entrepreneurship and management experience, so that high quality teaching staff is required. The effectiveness of college enterprise education cannot be improved without a group of professional and talented teaching staff. But the reality is that enterprise education courses are taught by economics and management teachers or student instructors in most colleges after short-term training. On one hand, these teachers lack entrepreneurship and company operation practice. On the other hand, they have not done professional research studies of enterprise education, which leads to monotonous content and old-fashioned teaching methods. This kind of courses cannot arouse students' interests or innovation awareness. In this dilemma, some winners become scare and popular resources as enterprise education teachers. They often share their practical experience with students by means of lectures and reports which are limited by time, place and form, so that these business winners cannot play a long-term role in guiding students.

\subsection{Enterprise Education Lacking Scientific Evaluation and Feedback Mechanism}

In recent years, the situation in the job market is getting more and more intense, while the government pays more and more attention to college students' employment and entrepreneurship. Almost every college invests large numbers of human, financial and material resources into students' enterprise education. As a kind of education behavior, the ultimate teaching effects are vital. However, the evaluation and feedback mechanism in most colleges have problems in the implementation process.

In some colleges, the evaluation system on enterprise education is limited to students, ignoring enterprise education facilities, settings and assist obtained from the society.

Some colleges take numbers as the only standard to check enterprise education teaching effects, such as the numbers of entrepreneurship activities, numbers of students taking parts into enterprise competitions, numbers of entrepreneurship program plans and so on. This kind of single indicator will cause extensification and utilitarianism of college enterprise education.

Some colleges only have simple evaluation system, lacking corresponding feedback system. Feedback mechanism should run throughout college enterprise education, so that administrators can collect feedbacks from all parties and make corrections and optimization in time.

\section{Optimization Plan for Management Effectiveness of College Enterprise Education}

The promotion of enterprise education in colleges is a systematic project, which needs multiple curriculum, practical experience platform, healthy campus culture environment, proper personnel training system and so on. Therefore, scientific and reasonable planning should be carried out, aiming at students' subjectivity development [9].

\subsection{Setting Proper Concept and Educational Objective}

The educational training model of China mainly focuses on exam-oriented education, which causes the problem that students lack innovation and entrepreneurship abilities. Students under this model dare not to try new things, and lack the courage or boldness to adapt to new situations. It has been found that the exam-oriented education model is out of the need of society.

The effectiveness optimization of college enterprise education work has to set the right objectives from top to 
down first. The idea of regarding enterprise education as exam-oriented education should be changed. Enterprise education is not equal to teaching students to start business or be boss. Actually, enterprise education is a kind of quality-oriented education, which aims to cultivate compound talents with innovative spirits and entrepreneurship thoughts.

To set proper and reasonable educational objectives is not only a reform to enterprise education, but also relocation for enterprise education. On one hand, colleges should integrate various resources to optimize and innovate the teaching methods and contents. On the other hand, colleges should develop enterprise education to something that value students' consciousness and spirits.

\subsection{Setting Enterprise Education Curriculum Rationally, Enriching Teaching Methods}

Proper and scientific enterprise education curriculum is beneficial to develop students' innovation awareness and comprehensive abilities for entrepreneurship, which is the direct stage that influences the effectiveness of college enterprise education. Enterprise education originates from western countries where the development of enterprise education is more sophisticated, especially in curriculum setting which pays more attention to cultivate students' independent consciousness and innovation abilities [10]. The curriculum setting of domestic enterprise education should be based on the goal system, covering career consciousness, enterprise knowledge, competence and practical operation. The concrete curriculum setting types and contents are shown in Table 1 [11].

Table 1. The Main Curriculum Setting Types in Domestic Enterprise Education.

\begin{tabular}{ll}
\hline $\begin{array}{l}\text { Types of Enterprise } \\
\text { Curriculum }\end{array}$ & Main Learning Contents \\
\hline Career consciousness & $\begin{array}{l}\text { Idea motivation, opportunity assessment, etc. } \\
\text { Marketing, venture investment, intellectual } \\
\text { property, etc. } \\
\text { Enterprise knowledge }\end{array}$ \\
Team organization, communication \\
management, market development, etc. \\
Pusiness plan setting, entrepreneurial \\
Practical operation & competition, opportunity selection, etc. \\
\hline
\end{tabular}

Curriculum setting at home can take excellent foreign colleges' experience as references. For example, exercise curriculum for enterprise education is offered in the University of Worcester, inspiring students to start business in sports areas with physical knowledge. In order to encourage students to find business opportunities in golf sports, golf is combined with enterprise education in University of Central Lancashire. Professional enterprise course of Surf Science and Technology is designed in University of Plymouth [12].

The domestic enterprise education should use curriculum setting methods and thoughts in foreign colleges for references. However, bringism ought to be avoided, in that regional characteristics, comprehensive abilities and resources should be considered in the curriculum setting. Moreover, the cooperation and coordination between enterprise education and other disciplines need to be noticed, so as to improve students' enterprise education knowledge and professional skills at the same time.

Students' passion for enterprise education will be reduced in the single classroom teaching environment, which has a direct effect on the effectiveness of enterprise education. Therefore, colleges should enrich enterprise education carriers as the direct approach to improve effectiveness. The teaching methods of enterprise education should encourage the involvement and motivation of students as strong as possible. This is the basic principle of teaching methods, including openness and flexibility. Except for classroom teaching, colleges may attach importance to the second class activities and entrepreneurship incubator base, which can promote the diversified development of enterprise education curriculum. In this way, students can penetrate into entrepreneurship practice and lectures through various approaches. According to Chinese College Students Employment and Enterprise Development Report in 2015, the most popular enterprise education types are practical training in innovation parks, companies, KAB teaching or ERP teaching of sand table, which occupies the proportion of 20.56 percent, 20.23 percent and 13.05 percent respectively.

\subsection{Improving the Teachers' Level and Making Enterprise Education Specialized}

Teachers for enterprise education are different from teachers in other disciplines. They not only teach the basic entrepreneurship knowledge, but also infect students with their entrepreneurship passion and faith. In this circumstance, teachers of enterprise education are required to have solid professional knowledge and essential practice experience. Only expert teachers, combining practice and theory together, can improve the quality of college enterprise education. The present entrepreneurship teachers are manly amateur, consist of teachers in economics and management and instructors. These teachers lack the ruling ability of this new branch of science. To address this problem, it is important to strengthen teachers' specialized training and introduce social mentors as well.

On one hand, the specialized level of present teachers should be improved, which is helpful for the upgrading from part-time teachers to professional staff. Teachers for enterprise education should be engaged in new high-tech enterprise, enhancing the involvement in the integration of producing, studying and research. The actual experience in enterprise is beneficial to collect cases, which contributes to establish a professional team. This team consists of teachers who are in charge of teaching and research specially, devoting themselves into college enterprise education heart and soul.

On the other hand, social mentors can be introduced into college enterprise education. Some entrepreneurs with passion, abilities and practice experience can be invited to offer courses in colleges. Some technical experts can be 
introduced as brain trust members and social mentors to offer instructions and help for students.

\subsection{Inventing Evaluation and Feedback Mechanism for Effectiveness of College Enterprise Education}

The present evaluation system for college enterprise education mainly focuses on using single data to measure education effects. This single evaluation principle is lack of comprehensiveness and objectivity [13]. Rational and scientific evaluation system includes the comprehensive evaluation on effectiveness of college enterprise education, the government, companies, the surroundings and other aspects. Only with the summary of all evaluation aspects, the weakness part of college enterprise education can be found out. Besides, students, as the educated ones, are the key parts of examining education effects. Students' entrepreneurship awareness, ideas and abilities after education should be taken into evaluation except for their involvement in enterprise activities [14].

The normalized feedback mechanism of track should be established except for proper evaluation system. The feedback information can be used as essential basis for course adjustment and enterprise education reform, which plays an important part in improving the effectiveness of enterprise education. The feedback system of students, teachers and government to enterprise education should be established respectively.

Students are the major educated objects of enterprise education. They have the most direct and realest feelings and experience towards enterprise education. Teachers can adjust their teaching methods and contents in time according to the feedbacks from students.

Teachers, as the teaching subjects of enterprise education, can find out students' psychological characteristics, receptivity and interests, based on which teachers can propose proper modification and adjustment for college enterprise education modes.

It's significant for the government, as the regulator of enterprise education, to provide feedback on enterprise education. Colleges should collect feedbacks from the government actively. Analyzing these feedbacks, colleges can adjust enterprise education plans and objectives, which will make college enterprise education more specifically.

\section{Conclusion}

The key concept of management effectiveness in college enterprise education is the maximum using of integrated resources, including human, material and financial resources, which concerns the core competence and healthy development of colleges. To improve the effectiveness of enterprise education, colleges should reform the management thought, enrich teaching modes and optimize faculties. Meanwhile, college, students and social functions should be combined organically to form educational composite force, offering powerful protection for cultivating high-quality enterprise talents.

\section{References}

[1] Ren Luyao, Yang Zengxiong. Entrepreneurship Education: the Third Passport for Education-a Review of Foreign Entrepreneurship Education Research [J]. Education Research Monthly, 2010 (11).

[2] Chen Xuejun. An Overview on Enterprise Education in Foreign and Domestic Colleges [J]. Journal of Chongqing University of Science and Technology (Social Science Edition), 2015 (1).

[3] Lu Xianxian. Guangxi College Students Entrepreneurship Education Effectiveness Research-Sample Survey Based in Nanning Universities [D]. Guangxi University, 2012.

[4] Liu Weixing, Jia Yuzhuo. Domestic College Students' Enterprise Education System Based on System Thingking [J]. Continue Education Research, 2012 (7).

[5] Li Chenghu, Gao Yun. Analysis on the Current Situation of Domestic College Enterprise Education [J]. Higher Agricultural Education, 2010 (8).

[6] Chinese College Students Employment and Enterprise Development Report 2015

[7] Yang Jichun. A Study on the Problems and Response Strategies in College Students' Entrepreneurship Education [J] Journal of Northeast Normal University (Philosophy and Social Science), 2016 (1).

[8] Zhang Rui, Wang Deqing. Problems and Suggestions for Domestic College Enterprise Education [J]. Education Exploration, 2008 (7).

[9] Meng Xin, Hu Hanhui, Ynag Wenxie. Problems and Countermeasures of College Enterprise Education- A Case Of Jiangsu Province [J]. Joumal of Southeast University Philosophy and Social Science, 2015 (3).

[10] Yao Fei, Gao Dongxue, Sun Tao. The Developmental Pathways and Key Elements of University- based Entrepreneurship Ecosystems: An Comparison between Two Typical Cases in US and Singapore [J]. International and Comparative Education, 2016 (1).

[11] Li Chunqin. Research on College Enterprise Education System Construction [J]. China Adult Education, 2007 (8).

[12] Lu Lihua. Characteristics of Enterprise Education in American Universities and Its Inspirations [J]. Studies in Foreign Education, 2007 (5).

[13] Wang Jianxue, Yang Tuzhen. A study of entrepreneurship education in Vocational College [J]. Theory and practice of education, 2010 (33)

[14] Xue Hao, Chen Guixiang. A Study on the Construction of Evaluation System of Support Policy on Business Startups for College Students [J]. Journal of National Academy of Education Administration, 2016 (3). 